\title{
Bergson literato - ensaio sobre o estilo de composição do texto filosófico
}

\section{Bergson as a writer - essay on the style of composition of the philosophical text}

\author{
Yves São Paulo \\ Doutorando em filosofia pela UFBA
}

Resumo: neste ensaio buscaremos realizar incursão no estilo de escrita filosófica e as influências que os artifícios de composição do literato ficcionista podem exercer sobre a criação de um texto de filosofia, tomando o caso específico da filosofia de Henri Bergson, e como o uso de imagens e analogias, particularmente, desempenham papel especial no desenvolvimento da intuição como método para chegar à duração.

Palavras-chave: Henri Bergson; escrita filosófica; duração; intuição.

Abstract: in this essay we will seek to make an incursion through the style of philosophical writing and the influences that the fictional writer's artifice of composition can exert on the creation of the text of philosophy, in the specific case of Henri Bergson's philosophy and how the use of images and analogies, particularly, play special roles in the development of intuition as a method to reach the goal of Bergson's metaphysical contributions, duration.

Keywords: Henri Bergson; philosophical writing; durations; intuition. 
Não é novidade no mundo da literatura filosófica o flerte com a produção de imagens para não somente ilustrar a teoria desenvolvida, como também profundamente enraizar uma imagem no cerne do pensamento desenvolvido. É familiar ao leitor de filosofia ao menos uma imagem em particular, a caverna de Platão, que possui muito mais que o mérito de ser ilustração sobre a teoria das Ideias. Esta tomada estilística de escritores que se aventuram pelos campos da filosofia leva o pensamento a adentrar num campo além daquele da argumentação lógica, adentrando o universo do artista literato, do ficcionista, que nem sempre se encontra preocupado em convencer o leitor a respeito da validade de sua construção. Ainda assim, sua escrita é permeada por ideias e aos poucos estas ideias encontram espaço no espírito do leitor, se faça ele ciente disso ou não, especialmente por meio das emoções que evoca ao convidar quem lê para o interior de seu universo de letras.

O papel do filósofo, o leitor deste ensaio pode contrapor ${ }^{156}$, não é o de criar emoções - quando muito, como é o caso do esteta, é buscar certos padrões para poder comentar estas emoções. Mas há algo de muito próximo entre o artista literato e o trabalho literário do filósofo e que se encontram neste ponto das emoções, onde a criação de imagens traça sua correspondência entre ambos os pontos. Há o esforço criativo por parte do escritor, seja artista ou filósofo, em desenvolver suas imagens e de atingir algo mais que um percurso lógico em meio aos argumentos citados. Estas imagens são apresentadas ao leitor posteriormente às argumentações lógicas, mas não devem ser vistas apenas como reforço de argumentação ${ }^{157}$. Eis precisamente o ponto chave de nosso ensaio: o filósofo visto como

156 Este ensaio não é obra acabada, o próprio termo já o diz, o leitor pode questioná-lo, descartá-lo, concordar, discordar, construir com ele ou a partir dele, afinal, sendo ensaio, significa que não chegamos à noite de abertura.

157 Quando Platão, para recuperar o autor citado ao primeiro parágrafo, desenvolve a alegoria da caverna, ele retoma os argumentos desenvolvidos no Livro VI de $A$ república, porque algo mais pode a linguagem para fazer seus leitores (e ouvintes de Sócrates) a embarcar na aventura de conhecer. 
literato busca meios para envolver e fazer seu leitor enxergar o mundo com as mesmas lentes que ele (o filósofo).

No século XIX, o trabalho com imagens por parte dos filósofos se viu cada vez mais comum, especialmente ao lembrar um nome tão popular como o de Nietzsche. Mas outros ainda se valiam de certos recursos literários para a composição de seus ensaios e tratados. Um deles, que poderemos acompanhar algumas linhas mais adiante, foi Jean-Marie Guyau, autor de alguns ensaios de longo alcance entre os intelectuais de seu tempo, na segunda metade do citado século. Particularmente em um de seus ensaios, Guyau faz analogia curiosa entre a mente humana e um dispositivo tecnológico em voga em seu tempo, que ganhava cada vez mais popularidade, o fonógrafo. Analogia que pode ser vista como mero instrumento para aproximar sua argumentação do cotidiano e do leitor médio, faz mais do que isso e ganha um particular adepto que se vale de semelhante artifício décadas depois para compor um dos capítulos mais lembrados de sua obra mais famosa.

Falamos de Henri Bergson, que ao escrever A evolução criadora, se valeu da popularidade que ganhava o cinematógrafo à primeira década do século XX para traçar semelhante analogia àquela que Guyau fez em seu ensaio, entre a mente e um dispositivo tecnológico. Por meio desta analogia Bergson retoma muitas das formulações que já havia desenvolvido não somente em obras anteriores como na própria obra em questão. Poder-se-ia ainda interpretar esta analogia como meio encontrado pelo filósofo para saltar de um ponto argumentativo para outro, de um ponto da filosofia para outro, mas tal elipse poderia ser realizada sem a necessidade da criação de uma imagem tão cativa para seus leitores e que abarca certa popularidade em torno de sua obra.

Como posto, a criação de imagens faz mais do que ilustrar a teoria desenvolvida pelo filósofo, ela abarca o leitor e o introduz no pensamento desenvolvido. Mas na filosofia de Bergson este artifício se vê ainda mais necessário por um detalhe que não passa despercebido de seus leitores mais próximos: a duração não pode ser conceituada. Não podendo ser 
tratada como conceito, como chegar à duração? Temos antes que chegar a um meio termo, e o filósofo encontra este meio termo numa relação com o mundo das artes, com a invenção, a criação e a imaginação. Não à toa, tanto Guyau em seu ensaio quanto Bergson ao tratar o cinematógrafo, estão se aproximando de um diálogo com a duração, ainda que se posicionem em campos distintos.

Bergson, por sua parte, continuamente reconhece em seus escritos a capacidade do artista em reconhecer a vivacidade do mundo e inserir um pouco desta vivacidade dentro de sua obra. Caberia também ao filósofo que escreve sobre a vida encontrar um mecanismo para poder tratar a vida de tal maneira a dela se aproximar, de seu movimento inerente, evitando a imobilidade e estabilidade da argumentação filosófica tradicional faz parecer - o contraponto entre a objetividade da representação conceitual e a dinâmica da criação literária em sua força expressiva para levar o leitor a experimentar. Mas o que podemos notar de antemão é que Bergson faz mais do que reconhecer que o artista possui olhos privilegiados quando contempla a vida e a expõe em sua obra; também Bergson toma para si um pouco deste elixir e insere em seus escritos algo da mobilidade da vida, o fluxo dos pensamentos, abrindo o mundo das letras filosóficas para a intuição da duração.

O objetivo de nosso ensaio não é o de realizar exegese das obras de Guyau e Bergson, ou da possível influência de Guyau sobre Bergson, mas pensar o estilo de composição literária que o filósofo desenvolve ao longo de suas obras, e que neste caso resvala na criação de imagens, metáforas e analogias. Mostraremos como Bergson se vale de um recurso estilístico para enriquecer o desenvolvimento de sua própria teoria metafísica, como seu estilo de escrita encontra seu método de investigação.

\section{2}

Na década de 1880, Jean-Marie Guyau escreve ensaio intitulado A gênese da ideia de tempo, publicado postumamente com o auxílio editorial de Henri Bergson. Sem dúvida, como 
bem aponta Regina Schopke na introdução à edição brasileira do citado texto, esta obra influiu sobre a mente do escritor que viria a compor sua filosofia da duração (SCHOPKE, 2010, p. 9) ${ }^{158}$. O que nos chama particular atenção neste ensaio de Guyau é o capítulo quatro, quando decide tomar o caminho por traçar uma analogia entre a memória e o fonógrafo. O que nos convida a passear por estas páginas não é somente a analogia em si, mas as palavras tecidas pelo filósofo antes de inserir sua analogia no corpo de seu ensaio. Estas palavras são dirigidas ao uso da analogia como recurso tomado pelos autores de "ciência", ou escritores de textos filosóficos, para poder ampliar sua capacidade de raciocínio em torno do tema apresentado.

A segunda frase de abertura do capítulo já nos oferece material para iniciarmos nosso percurso investigativo: "E se a analogia é o princípio da indução [...]” (GUYAU,2010, p. 85), escreve Guyau, por ora não nos fazendo necessitar do restante da frase por conta de um termo que devemos observar um pouco mais de perto, indução. Este pode ser compreendido de duas maneiras diferentes e igualmente plausíveis dentro desta formulação, uma sendo a analogia como possibilidade de abertura para que o leitor tome aquela construção de maneira mais ampla, a outra sendo a analogia como dirigindo a atenção do leitor para um ponto em específico da argumentação, ou seja, para uma conclusão objetiva. Qualquer um dos dois caminhos pode ser encontrado nas formulações científicas que se valem do recurso da analogia para esclarecer seu leitor, ora se valendo da imagem para fazer o leitor habitar naquele mundo, ora se valendo de uma imagem para direcionar sua visão para um caminho específico da argumentação.

De todo modo, a analogia é utilizada de modo a induzir o leitor a trilhar caminhos novos, de conhecimentos que não possui, sendo o uso da metáfora - e Guyau faz uma relação entre analogia e metáfora como se fossem sinônimos - meio para poder colocar este conhecimento novo tratado pelo filósofo em roupagem já bem conhecida por seu leitor. É trilhar o percurso desconhecido "através de superfícies já luminosas", a imagem deste $158 \quad$ A autora não entra em especificações sobre qual teria sido a influência de Bergson sobre o trabalho editorial do ensaio de Guyau. 
primeiro parágrafo é conhecida pelos curiosos de filosofia desde a antiguidade, o paralelo entre luz e a consciência inteligente, apontando para o desfecho do parágrafo com a seguinte frase - que certamente não passará despercebida a Henri Bergson e seus leitores: "Compreender é, ao menos em parte, lembrar-se" (Idem). Pode-se encontrar aqui algo do cerne da memória criadora que Bergson trabalhará, antes encontrando a criação de conhecimento por meio de analogia, quando a novidade escrita pelo filósofo ou cientista é tratada por meio de uma imagem bem conhecida de seu leitor, fazendo em parte com que este conhecimento novo se enraíze mais fundo em sua consciência por meio de uma vinculação com algo que faz parte de sua vida há mais tempo que o texto lido. Devemos, contudo, ainda sublinhar que Guyau não escreve "aprender", mas "compreender", e por isto apontando que não se trata de algo de realmente novo, mas de algo que o leitor já tem algum contato, reforçando nossa colocação de que a analogia aparece nos textos não como ponto principal, e sim como artifício de reforço de argumentação, não para que o leitor "aprenda", mas "compreenda".

É com muita clareza que Guyau demonstra que o uso de imagens não é incomum entre os escritores que se aventuram compreender as faculdades psíquicas, e é precisamente para este ponto que também ele se valerá de analogia, porque como ele mesmo coloca, "antes de saber, é preciso começar por imaginar" (Idem, p. 86). Por meio deste exercício é possível traçar comparações e encontrar semelhanças no exercício realizado por ou com o auxílio de um objeto e aquele desenvolvido pela mente. O que não faz com que algumas destas analogias adentrem em campos equivocados, dando ao cérebro humano as características que são próprias aos objetos em sua passividade, esperando por ser utilizados exatamente pela mente humana. Em outras palavras, são postas como faculdades psíquicas humanas qualidades estáticas que cabem especificamente aos objetos utilizados nas analogias, quando a analogia deveria servir para abrir a argumentação para alcançar o dinamismo das faculdades do cérebro humano. Ao abordar as lembranças é preciso se fazer ciente de que não se trata somente de o cérebro receber e guardar informações, sendo uma troca realizada, 
algo que compreendesse o papel dinâmico do cérebro. É assim que Guyau chega ao objeto que crê mais apto a ser comparado ao cérebro humano, o fonógrafo de Edison.

Podemos daqui concluir que existem certas precauções no uso de analogias, mas que elas servem para quebrar a objetividade e a estabilidade da linguagem ordinária utilizada em ciência e filosofia; artifício perfeito, portanto, para escrever não somente sobre o cérebro humano, as faculdades psíquicas, como também para comentar sobre a lembrança, a memória, o presente, o contingente, enfim, a duração. Abre-se aqui um caminho para que possamos adentrar na filosofia de Henri Bergson.

\section{3}

Dentre os objetos que poderia escolher para traçar analogia com as faculdades psíquicas, para utilizarmos ainda o termo de Guyau apesar de não ser o mais adequado para o presente caso, Henri Bergson escolheu aquele de crescente popularidade em todo mundo e que poderia orgulhosamente ser chamada de invenção francesa, o cinematógrafo. Contudo, a aproximação passível de ser feita entre os autores em questão encontra um percalço quando notamos que a argumentação desenvolvida como introdução por Guyau para justificar seu uso de uma analogia não se encaixa perfeitamente na analogia do cinematógrafo feita por Bergson. Ainda assim, podemos apontar as devidas similaridades entre os dois autores e que Bergson teria pagado seu débito com a filosofia de Guyau e até mesmo com a forma com que este autor escrevia em forma ensaística com seu exemplo com o cinematógrafo; Bergson paga sua dívida com Guyau com uma ida ao cinema.

É natural que existam diferenças radicais entre a obra de dois autores que procuram certa originalidade, especialmente no caso daquele que se apresenta como leitor, absorvendo o que foi lido e abarcando a seu próprio mundo, como é o caso particular de Bergson. O caso é que o uso do cinematógrafo como analogia em $A$ evolução criadora não é feito de tal modo a considerar o cinematógrafo como exemplo de funcionamento 
de todo o sistema da consciência, como se estivesse a considerar esta máquina o caso mais extraordinário de exemplo de funcionamento do espírito humano. Bergson toma a imagem do cinematógrafo para se referir a uma faceta do espírito humano, ao que podemos chamar de inteligência analítica.

Esta é uma analogia controversa de ser encontrada na filosofia de Bergson, sendo famosamente contestada até mesmo por alguns de seus mais notáveis leitores, como Gilles Deleu$\mathrm{ze}^{159}$. Uma das semelhanças, ou dívidas, da analogia realizada por Bergson com aquela feita por Guyau é a escolha por uma máquina que consegue realizar seu trabalho de modo automático, ou seja, sem a necessidade de uma pessoa a constantemente permanecer por perto - o que era uma realidade nos primeiros tempos do cinematógrafo que funcionava a manivela, mais tarde virando característica obsoleta. O que em parte consegue abarcar algo do dinamismo que Guyau defendia no uso de um artifício como a analogia ao comentar o cérebro humano ${ }^{160}$.

Poder-se-ia considerar o cinematógrafo como exemplo para apontar as mais variadas evoluções que transcorrem perante as lentes da máquina, mas Bergson volta seus olhos para outro aspecto do dispositivo em questão, e ao invés de analisar a experiência tida frente ao que é registrado pelo cinematógrafo ele prefere se voltar para a formalidade do funcionamento do aparelho. Isto porque o funcionamento do aparelho e o funcionamento do pensamento analítico se dão de maneira muito semelhante, num retorno à filosofia de Zenão, quando todo movimento é equiparado entre si e remontado a partir de estágios do corpo movente no espaço. Assim como o pensamento analítico ignora o esforço do braço para alcançar o copo com água na outra ponta da mesa, se voltando para a ação realizada de tomar o copo e o trazer para próximo de si, a câmera de filmar desmonta o corpo em movimento em estágios iguais. Não se trata de falar de duração, neste caso, mas de pensar o tempo

\footnotetext{
159 Como pode ser atestado no primeiro capítulo de seu $A$ imagem-movimento.

160 É preciso que tenhamos claro que concernindo a filosofia de Bergson não é correto utilizarmos o termo "cérebro" para nos referirmos a faculdades da consciência.
} 
a partir de caracteres espaciais, decompondo o movimento em seu absoluto e o transformando em estágios passíveis de ser decompostos e recompostos partindo de princípios quantitativos. É a isto que Bergson chama de "mecanismo cinematográfico do pensamento" (BERGSON, 2005, p. 331).

No entanto, esta imagem é utilizada por Bergson para apontar justamente o oposto do que defendia Guyau e do que vínhamos buscando defender acerca da filosofia do próprio Bergson, que é o uso de imagens para abrir a possibilidade de mais a fundo enxergar uma filosofia e seu dinamismo. No caso da analogia com o cinematógrafo, não é um lado dinâmico das faculdades da consciência que Bergson procura apresentar, mas antes um aspecto maquinal, que tratará todas as situações em igualdade independente da situação que seja, como se houvesse apenas um devir a ser encontrado na natureza, o que de antemão ele já apresenta como não sendo o caso. O movimento que leva do verde para o amarelo não é semelhante àquele que leva do verde para o azul, assim como o movimento que leva da flor para o fruto numa planta não se assemelha ao movimento da larva para a ninfa e da ninfa para o inseto acabado; na natureza encontramos devires variados infinito (Idem, p. 329), mas perante a máquina de filmar eles são todos semelhantes, ao menos quando analisamos o procedimento formal da captura dos 24 quadros por segundo. Porque qualquer um dos movimentos tratados acima, a máquina obedecerá ao número de quadros estabelecido antes de começar a gravar, e assim o fará também o equipamento de exibição do filme registrado, movimento semelhante àquele realizado pelo pensamento analítico que independente do movimento encontrado adotará o mesmo padrão: a mão sai do ponto de repouso $\mathrm{A}$, passando por $\mathrm{B}$, encontrando o copo com água em C.

Subjaz à analogia com o cinematógrafo o esforço de imaginação para apresentar uma maior riqueza da experiência cotidiana com a natureza, enxergar os movimentos em sua característica qualitativa e não quantitativa, assim abandonando o mundo das máquinas e dos números e se aproximando um pouco mais daquele mundo dos artistas e, em ultimo caso, dos 
filósofos. O pensamento analítico comparado ao cinematógrafo tem finalidades estritamente práticas, extinguindo o devir variado da natureza para impor sobre o mundo ao seu redor os ditames do próprio ato sobre as coisas; o papel da inteligência é presidir ações (Idem, p. 323). É aspecto de abstração da inteligência, de afugentar da realidade uma de suas características essenciais, a duração das coisas, a passagem, o fluxo inerente às coisas com as quais lidamos. Tudo isso que pode ser reconhecido não ao abandonar a inteligência por completo, mas sim ao buscar adentrar nas próprias coisas analisadas, procurando intui-las. Eis o caminho para uma nova metodologia para o trabalho filosófico e que pode também fornecer algumas pistas sobre o caminho do trabalho com analogias em filosofia, e aproximar o exercício de Henri Bergson de experimentar a duração.

O uso de imagem por parte de Bergson se refere antes de tudo à aversão da duração pela representação, porque nenhum conceito pode abordar por completo o significado de duração; mas também não pode uma imagem. Como pode então Bergson se valer de imagens, como vínhamos anunciando, quando as imagens não podem realizar a representação da duração e, mais ainda, a duração não pode ser representada objetivamente? A contrariedade do filósofo neste ponto se encerra na problemática da objetividade da representação conceitual, porque o que é objetivo não pode ser utilizado para realizar uma representação clara do que não é objetivo ${ }^{161}$. No fim das contas, se tentarmos realizar uma representação da duração do eu estaríamos a realizar semelhante trabalho àquele que a analogia do cinematógrafo denuncia, a quebra da contingência (BERGSON, 1974, p. 25).

Como, então, chegar à duração, que é o objetivo de Bergson, quando é impreciso realizar uma representação da du-

$161 \quad$ Portanto, o termo contrariedade utilizado aponta para o caso de uma imagem não ser suficiente, mas a pluralidade de imagens desenvolvidas ao longo de sua composição escrita leva o leitor a notar que há algo a ser intuído: a duração. 
ração? Não é somente por meio da representação conceitual que um filósofo pode chegar ao seu objetivo, e Bergson encontra este caminho por meio de um inquérito metodológico. Devemos abandonar aquele sistema apresentado como sendo o pensamento analítico para encontrar outro método que nos dê contato mais direto com a duração. Não é preciso para isto que inventemos algo de completamente novo e desconhecido da humanidade, este método já se encontra muito bem enraizado em algumas atividades muito bem conhecidas, como a criação artística; a este método Bergson chamará de intuição.

O que é afinal a intuição? Famosa é a resposta que Bergson fornece a esta questão ao escrever que intuição é a simpatia que temos por alguma coisa, por um objeto ou pessoa, e que nos transporta para seu interior (BERGSON, 1974, p. 20). Se por meio do pensamento analítico nos posicionamos externamente à coisa e estabelecemos seu movimento como estados sucessivos no espaço, por meio da intuição adentramos no próprio movimento e o percebemos como um todo. $\mathrm{O}$ que não acontece somente com o movimento físico, dos corpos a se deslocar no espaço, também sendo palpável o movimento espiritual das coisas, quando esse adentrar diz respeito a muito mais que simplesmente o balançar de galhos de árvores ou o sorriso no rosto de uma pessoa - podemos ainda levantar uma pergunta retórica sobre este ultimo ponto: é possível dizer que uma pessoa está alegre sem a necessidade de vermos estampada em seu rosto um sorriso?

Eis então uma querela a ser trabalhada por Bergson em seu desenvolvimento teórico: como então fazer o leitor de sua filosofia intuir a duração? A resposta para esta pergunta vem clamando por espaço há algumas páginas: imagens. O que nos faz retornar ao princípio deste tópico, não escreveu Bergson que a duração não pode ser representada? Como podemos estar a voltar atrás neste momento e dizer que o meio para levar a uma intuição da duração se dá por meio de imagens? O importante neste ponto é prestar atenção no plural: imagens não imagem.

É em Introdução à metafísica que Bergson escreve: "A metafísica é, pois, a ciência que pretende dispensar os símbolos" 
(Idem, p. 21), por isso fazendo da intuição um método tão valioso para Bergson, porque com ela não há a necessidade de se valer de símbolos conceituais para poder tratar a duração, antes levando o leitor à intuição desta metafísica. O caso é que apenas uma imagem não é suficiente para a realização deste trabalho de intuir a duração, uma imagem permaneceria no mesmo campo de representação que Bergson busca escapar na sua metafísica.

É preciso um conjunto de imagens diversificadas para poder dirigir a consciência a notar que há uma intuição a ser apreendida. É preciso admitir que nenhuma destas imagens por conta própria fará o trabalho solitário de representar sozinha a duração, porque não é possível fazer a representação da duração. Apenas por meio de um trabalho conjunto das imagens chega-se ao ponto de admitir que há uma intuição a ser realizada (Idem, p. 23). Portanto, entra aqui o trabalho do filósofo de se aproximar do literato artista e criar imagens as mais diversificadas para apresentar ao seu leitor e levar a consciência a intuir a duração.

Portanto, quando Bergson se vale do cinematógrafo para traçar uma analogia com o pensamento analítico, é importante notar que se trata de um procedimento que cria uma representação da mesma ordem da faculdade do espírito que a analogia está a traçar. Um trabalho de mesma natureza não poderia ser realizado sob os mesmos termos para poder comentar sobre aspectos mais amplos da consciência ou do espírito, uma vez que a duração não comporta uma representação tão objetiva e conceitual a ponto de ser resumida a uma fórmula, como Bergson pôde resumir o pensamento analítico a uma fórmula. O pensamento analítico é precisamente aquele que trabalha com fórmulas e representações.

Há então aqui uma cisão entre Bergson e Guyau, um de seus inspiradores, quando notamos que o vocabulário utilizado pela ciência é tomado com destreza por Guyau para o desenvolvimento de suas formulações filosóficas, mas para Bergson ela se mostra como que falha. Por meio de uma representação conceitual a duração poderia ser delimitada por multiplicidade, unidade, continuidade, divisibilidade..., quando cada um des- 
tes conceitos mostram certa reserva quando em presença uns dos outros, assim como não conseguindo substituir a intuição (Idem, p. 24).

Para o filósofo, então, as competências do literato. O trabalho do escritor consiste em tomar as palavras - a primeira vista signos cerrados e abstratos, objetivos - e transformar em algo de novo, tomar conotações diferentes daquelas que poderíamos imaginar. O que não ficaria somente no trabalho com a significação das palavras, antes caminhando num sentido muito mais próximo daquele que Bergson aponta, a intuição. Ao tomar um romance ou um poema em mãos, as incursões feitas pelo autor não se veem restritas a descrição de situações, o que nos remete à pergunta retórica que levantamos algumas linhas antes: é possível dizer que alguém está alegre sem ver um sorriso estampado em seu rosto? Por meio da arte do literato, podemos adentrar com profundidade no psicológico de suas personagens, de suas criações, tudo isto a partir de seu trabalho com as palavras.

É trabalho semelhante àquele que o filósofo precisa procurar, mas com a clareza de saber que seu trabalho é distinto daquele do romancista. Não cabe ao romancista delimitar o que é a duração, ainda que por meio de seu romance faça seu leitor experimentar a duração. O trabalho do metafísico, neste caso, é tomar conjuntos de imagens para se livrar dos símbolos que impedem seu encontro direto com as coisas, fazendo com que fique num entremeio entre seu pensamento abstrato e a abstração dos símbolos que utiliza. A intuição é ato simples (Idem, p. 25).

\section{5}

Uma pergunta é levantada por Bergson em conferência reunida no volume $O$ pensamento e o movente sobre a capacidade de se ver além do que a percepção naturalmente nos oferece. Tomando apenas a atenção em direção a um objeto o vemos com cada vez mais clareza, mas estaríamos apenas a anotar mais e mais características sobre ele. Por outro lado, há 
séculos algumas pessoas de gênio vêm nos oferecendo a capacidade de ir um pouco além neste debruçar sobre as coisas e enxergar mais do que a coisa aparentemente nos oferece num contato imediato com ela. Estas pessoas são os artistas, que tomam as coisas mais ordinárias de nossa vida e as transformam de modo extraordinário para que as experimentemos além de sua faceta já bem conhecida. Os olhos do corpo e do espírito, portanto, podem enxergar para além do que podem alcançar a um primeiro momento. (BERGSON, 2006, p. 155)

É esta capacidade que possuem os artistas que Bergson busca levar não somente para sua escrita, mas também despertar em seu leitor, na tentativa de fazer despertar aquilo que estabelecemos algumas páginas antes como sendo seu método, a intuição. É por meio da intuição que o artista consegue olhar para as coisas e enxergar mais do que a atenção forneceria, porque consegue adentrar nelas, e imerso na criação de sua obra pintar diferentes matizes de emoções que são sugeridas para seus espectadores e leitores e ouvintes. Quando um romancista ou um poeta, lembra Bergson, escrevem sobre os estados de alma de suas personagens, não o faz de tal modo a montar estes estados de alma peça por peça, fazendo direta alusão aos sentimentos das personagens, como poderia ser retratado por uma frase simples e direta como "Susana tem fome". Antes, o literato adentra no próprio estado de alma de sua personagem, dissecando as angústias que aquele estado trazem para ela, assim podendo com graça pintar estes estados para seu leitor, que desta vez por meio da leitura adentrará nos estados de alma daquela personagem, recuperando em sua própria vida as lembranças e emoções que até mesmo nem sabia ter sentido algum dia. (Idem)

O que quereria um filósofo com estas características tão próprias à arte no desenvolvimento de sua filosofia? Uma imagem que Bergson desenvolve em seu Ensaio sobre os dados imediatos da consciência pode nos ajudar a chegar à resposta a esta pergunta, quando o filósofo escreve sobre caminhar por ruas que não conhece, de uma cidade nova, todos aqueles muros estranhos, e que a cada novo passeio vão-se tornando cada 
vez mais familiares aos olhos, não somente aos olhos do corpo, como também aos do espírito, pois aquela paisagem mais profundamente se marca em nós. (BERGSON, 1988, p. 101) Tratase de uma imagem anônima, no sentido de que uma personagem não é criada, não diz respeito à consciência de ninguém em especial, e ainda assim o leitor consegue ver-se implicado nela por meio de um exercício de imaginação, quando este artifício criado pelo escritor passa a fazer mais que descrever uma sequência de argumentos lógicos para sugerir certos estados de espírito, e mais do que isso, apontar para certa intuição a ser apreendida. Não se trata de somente enxergar o exemplo em sua particularidade de ambiente e situação, trata-se de notar o papel que desempenha em meio à filosofia que busca explanar a respeito da duração, sugerindo por meio de uma composição literária a intuição da duração, e como suas faculdades de consciência se desenvolvem dentro da duração.

\section{Referências}

BERGSON, Henri. Introdução à metafísica. Trad. Franklin Leopoldo e Silva. In Os pensadores: Henri Bergson, cartas conferências e outros escritos. $1^{\text {a }}$ ed. São Paulo: Abril Cultural, 1974, 17-45p.

BERGSON, Henri. Ensaio sobre os dados imediatos da consciência. Trad. João da Silva Gama. $1^{\text {a}}$ ed. Lisboa: Edições 70, 1988, p. 179.

BERGSON, Henri. A evolução criadora. Trad. Bento Prado Neto. $1^{\text {a } e d . ~}$ São Paulo: Martins Fontes, 2005, 398p.

BERGSON, Henri. A percepção da mudança. Trad. Bento Prado Neto. In O pensamento e o movente. $1^{\mathrm{a}}$ ed. São Paulo: Martins Fontes, 2006, p. 149-182.

GUYAU, Jean-Marie. A gênese da ideia de tempo. Trad. Regina Schopke, Mauro Baladi. $1^{\mathrm{a}}$ ed. São Paulo: Martins Fontes, 2010, 287p.

SCHOPKE, Regina. Guyau e o tempo que não passa. In A gênese da ideia de tempo. Trad. Regina Schopke, Mauro Baladi. $1^{\mathrm{a} e d}$. São Paulo: Martins Fontes, 2010, 287p. 